\title{
Ossificação da sutura palatina mediana após o procedimento de expansão rápida da maxila: estudo radiográfico
}

Omar Gabriel da Silva Filho*, Guilherme Fernandes Graziani**, Rita de Cássia Moura Carvalho Lauris ${ }^{\star \star \star}$, Tulio Silva Lara****

\begin{abstract}
Resumo
Objetivo: o presente trabalho tem como objetivo acompanhar radiograficamente a evolução da ossificação da sutura palatina mediana em pacientes submetidos à expansão rápida da maxila, bem como comprovar a validade de se avaliar a neoformação óssea através deste exame complementar de diagnóstico. Metodologia: a amostra constou de 38 pacientes no estágio de dentadura mista que se submeteram ao protocolo de expansão rápida da maxila, sendo $2 / 4$ de volta pela manhã e 2/4 de volta à noite, totalizando 1 volta completa por dia, compreendendo um período de 7 dias. Resultados: radiografias oclusais de maxila tomadas no pós-tratamento evidenciaram uma variação individual quanto ao período necessário para a completa neoformação óssea da sutura palatina mediana. A imagem radiográfica apresentou-se como um método confiável para a determinação da época correta de remoção do aparelho expansor. Tendo em vista a estabilidade pós-tratamento a longo prazo, o aparelho expansor deve ser removido somente após a completa ossificação da sutura. Conclusões: os resultados revelaram que são necessários mais de três meses para que o processo de ossificação e reorganização sutural se processe após o procedimento de expansão rápida da maxila.
\end{abstract}

Palavras-chave: Expansão rápida da maxila. Diagnóstico por imagem. Ortodontia. Sutura.

\section{INTRODUÇÃO E REVISÃO DE LITERATURA}

A sutura palatina mediana é rompida abruptamente durante o processo de expansão ortopédica da maxila e se reorganiza rapidamente, mediante reparo do tecido conjuntivo e formação de novo osso. Não há dúvida sobre esse comportamento biológico. Isso foi inferido inicialmente pelo pre- cursor do processo, o dentista americano Angel12,3 com base no diastema que se abriu entre os incisivos centrais superiores, já que não haviam sido descobertos ainda os raios X. Hass ${ }^{10}$ comenta, em seu artigo publicado em 1965, que o procedimento tal qual é aceito hoje, com ancoragem pesada, foi reintroduzido na Ortodontia dos Estados Unidos

* Ortodontista do Hospital de Reabilitação de Anomalias Craniofaciais da Universidade de São Paulo (HRAC-USP). Coordenador do Curso de Ortodontia Preventiva e Interceptativa da PROFIS, Bauru-SP.

** Residente do Setor de Ortodontia Corretiva do HRAC-USP, Bauru-SP.

*** Ortodontista do HRAC-USP. Professora do Curso de Ortodontia Preventiva e Interceptativa da PROFIS, Bauru-SP.

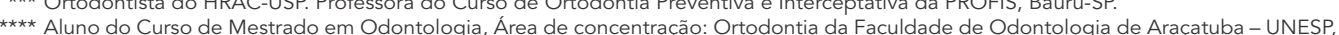

Araçatuba-SP. Ex-aluno do Curso de Aperfeiçoamento em Ortodontia Preventiva e Interceptiva da PROFIS/HRAC-USP, Bauru-SP. 
sob a influência da visita do professor Korkhaus na universidade de Illinois, em 1956. Passaram-se apenas três anos para que a expansão ortopédica viesse a ser objeto de estudo. Surgiu o primeiro estudo animal feito com porcos Duroc-Poland China para comprovar a possibilidade de abertura da sutura palatina mediana em até $15 \mathrm{~mm}$, usando ancoragem pesada para promover o efeito ortopédico sugerido por Angell. Os resultados desta tese foram notificados em artigo publicado por $\mathrm{Haas}^{11}$ no ano de 1961 e revelaram abertura da sutura palatina mediana seguida de neoformação óssea.

De fato, trabalhos prévios haviam cogitado a possibilidade de abertura da sutura palatina mediana em gatos $^{6}$ e em cães ${ }^{7}$; no entanto, os aparelhos utilizados empregavam ancoragem insuficiente para promover o tão almejado efeito ortopédico. Mesmo assim, esses estudos revelaram abertura da sutura palatina mediana de $0,7 \mathrm{~mm}$ na região anterior, sem efeito na região posterior do palato. Comentam ainda que a abertura da sutura palatina mediana foi acompanhada pela formação de novo osso nas margens suturais.

Um novo estudo histológico realizado por Cleall et al..$^{5}$ repetiu o trabalho de Haas em macacos, comprovando a ruptura da sutura palatina mediana e demonstrando a neoformação óssea progressiva subseqüente. No momento da ruptura observou-se a área do defeito ósseo preenchida com tecido conjuntivo fibroso desorganizado, bem vascularizado, sugestivo de resposta inflamatória crônica suave. Depois de três meses, a sutura apresentou um aspecto histológico similar aos macacos controle, mas o osso adjacente era irregular e muito celularizado, e não obedecia ao padrão lamelar usual do osso mais distante da área sutural, indicando haver uma formação óssea rápida. $\mathrm{O}$ aspecto histológico sugeria remodelação da sutura recém-reparada. Portanto, aos três meses, a morfologia sutural, quando avaliada radiograficamente, permanecia desorganizada e a área pobremente mineralizada quando comparada ao grupo controle. Após seis meses da fase ativa da expansão, a sutura mostrou-se bem organizada e histologicamente normal, mas o osso adjacente era de natureza irregular e não seguia o padrão lamelar normal. Somente no animal sacrificado com nove meses, a região sutural mostrou-se com grau de mineralização semelhante aos animais do grupo controle. Estudos realizados posteriormente ${ }^{4,6,16,17,19}$ comprovaram os mesmos resultados obtidos por Cleall et al. ${ }^{5}$

O único trabalho histológico em humanos com o objetivo de estudar o comportamento da sutura palatina mediana foi realizado em crianças de oito a treze anos de idade ${ }^{15}$. Três e quatro semanas após a expansão, conjuntamente ao alargamento da sutura, o tecido mostrou indícios de inflamação com acentuada atividade osteoblástica ao longo da superfície e processos ósseos. Cinco e seis semanas após, a ossificação progrediu, exibindo ilhas ósseas ao longo da sutura. Um ano após a expansão, a sutura completamente ossificada mostrava a formação de pontes ósseas nas margens suturais.

Este preâmbulo científico histórico vem levantar uma questão clínica importante no dia-a-dia: quanto tempo a sutura leva para se reorganizar completamente após a expansão rápida da maxila? Convencionou-se, após a publicação de artigos referentes ao assunto por Haas, que o tempo de três meses seria suficiente para a completa reorganização e ossificação do mecanismo sutural intermaxilar. No entanto, como os trabalhos de Cleall et al. ${ }^{5}$ e de Starnbach et al. ${ }^{19}$ sugerem, é provável que três meses não sejam suficientes para devolver a normalidade pré-tratamento à região da sutura palatina mediana. Para Hoffer Walters ${ }^{12}$, são necessários pelo menos seis meses para a sutura palatina mediana encontrar-se com o mesmo nível de ossificação do estágio inicial.

Do ponto de vista clínico, o controle da organização sutural até a porção média do palato é feito com facilidade mediante o emprego da radiografia oclusal total de maxila ${ }^{9}$. A neoformação óssea na região da sutura palatina mediana avaliada por meio da imagem radiográfica é indicativa de que o 
aparelho expansor pode ser removido.

Pensando nisso, alguns trabalhos se preocuparam em definir qual o tempo necessário para a total recuperação da sutura palatina mediana após o procedimento de expansão rápida da maxila. No final do primeiro mês de controle, após o término da ativação do parafuso expansor, já se observa o início da neoformação óssea, ainda difusa, na imagem radiográfica oclusal de maxila ${ }^{13}$ e esta ossificação progride com o tempo, até se aproximar do nível de ossificação pré-expansão. Alguns autores acreditam que em oito semanas o estágio de ossificação se aproxima do inicial ${ }^{13,15}$ ou no máximo em três meses, como demonstrado quando o nível de ossificação da sutura foi avaliado por meio de radioisótopo iodo ${ }^{8}$.

Simões et al. ${ }^{18}$, trabalhando com crianças no estágio de dentadura mista, utilizando a variação de densidade óssea em pontos específicos da sutura palatina mediana, observaram que a diferença entre as densidades ópticas pré-expansão e do terceiro mês de contenção é de 12,15\%, ou seja, houve apenas uma recuperação parcial na densidade óptica ao final do terceiro mês. Este achado indica que no período de três meses após a expansão rápida da maxila, a ossificação da sutura palatina mediana ainda não se completou, já que não apresentou as mesmas características de densidade óssea da fase pré-expansão.

\section{PROPOSIÇÃO}

Dada a importância do processo de neoformação óssea na região sutural após a expansão rápida da maxila, visando a estabilidade pós-tratamento a longo prazo, o objetivo do presente estudo foi avaliar o comportamento da sutura palatina mediana durante o período de contenção pós-expansão rápida da maxila, mediante imagem da radiografia oclusal, bem como comprovar a validade deste método de avaliação.

\section{MATERIAL E MÉTODOS}

A amostra reuniu 38 pacientes variando entre
6 e 11 anos, com idade média de 9 anos, sendo 19 do gênero masculino e 19 do gênero feminino, atendidos na clínica de Ortodontia Preventiva e Interceptiva da Profis/HRAC-USP, que se submeteram à expansão rápida da maxila com o aparelho expansor fixo tipo Haas. O protocolo de ativação do parafuso expansor constou de 1 volta completa por dia, sendo $2 / 4$ de volta pela manhã e 2/4 de volta à noite, compreendendo o período de 7 dias. A radiografia oclusal total de maxila foi o exame complementar utilizado para o diagnóstico da abertura da sutura palatina mediana e acompanhamento da neoformação óssea subseqüente. Radiografias foram realizadas no estágio de préexpansão e mensalmente, na fase de contenção, com o aparelho expansor mantido na boca, por um período médio de 4,5 meses.

O gráfico 1 ilustra a distribuição e período de acompanhamento radiográfico dos 38 pacientes que compuseram o grupo amostral.

Uma vez coletadas as radiografias, elas foram digitalizadas em um scanner com leitor de transparência, com uma resolução de 300dpi e ampliação de $100 \%$. As imagens foram salvas e identificadas para cada paciente. Após a conclusão da digitalização, as imagens foram dispostas lado a lado, obedecendo a uma ordem cronológica crescente, sendo a primeira radiografia tomada no estágio de pré-expansão e as subseqüentes, mensalmente, durante o período experimental.

Os exames visuais foram realizados por dois examinadores com formação em Ortodontia que indicaram a presença ou ausência de tecido ósseo neoformado na região da sutura palatina mediana, tendo como referência a imagem pré-expansão. As imagens da sutura palatina mediana nas radiografias oclusais totais de maxila foram classificadas de acordo com um critério subjetivo definido em escores que variaram de 1 a 4, como pode ser observado na figura 1:

1 - Ausência de ossificação;

2 - Ossificação difusa;

3 - Ossificação difusa e presença das margens 
ossificadas delineando a sutura nova;

4 - Sutura nova ossificada.

As imagens não passaram por quaisquer alterações de brilho ou contraste, sendo analisadas com a mesma qualidade em que foram digitalizadas. Os examinadores avaliaram, separadamente, as radiografias em um monitor de computador, em ambiente escurecido.

As avaliações foram realizadas duas vezes por um único examinador (Exl), num intervalo de três semanas e uma vez por um segundo examinador (Ex2) para que se pudesse calcular o erro do método. Foi utilizada a estatística de Kappa (k) para comparar os escores atribuídos às radiografias pelos dois examinadores entre si (avaliação interexaminadores) e pelo mesmo observador (avaliação intra-examinador).

\section{RESULTADOS}

A tabela 1 apresenta os valores de $\mathrm{k}$ e os níveis de concordância segundo o teste estatístico utilizado $^{1}$. Quando se aplicou a estatística de Kappa para a avaliação de concordância inter e intra-examinadores, observou-se um valor de $\mathrm{k}$ entre 0,61 e 0,80 , mostrando um nível de concordância bom entre as análises realizadas (Tab. 2).

\section{DISCUSSÃO}

O procedimento de expansão rápida da maxila envolve uma fase ativa, onde se aciona o parafuso até a almejada largura do arco dentário superior, e uma fase passiva, que usa o próprio aparelho como contenção até que a sutura palatina mediana se reorganize. Na fase ativa, a sutura se rompe e na fase passiva ela se reorganiza. $\mathrm{O}$ controle da abertura

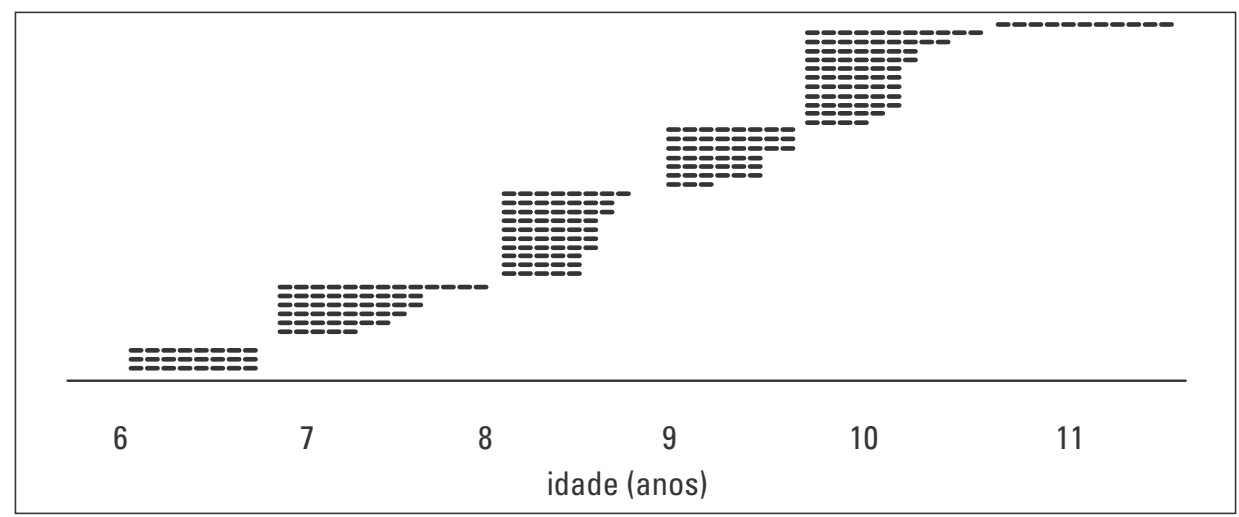

GRÁFICO 1 - Distribuição de acordo com os períodos de acompanhamento, por idade cronológica, de cada paciente do grupo amostral. Cada uma das 38 linhas representa um paciente da amostra.

Tabela 1 - Relevância do valor de k (Kappa) de acordo com nível de concordância descrito por Altman (1991)'.

\begin{tabular}{cc}
$\mathbf{k}$ & nível de concordância \\
\hline$\leq 0,20$ & pobre \\
0,21 a 0,40 & regular \\
0,41 a 0,60 & moderado \\
0,61 a 0,80 & bom \\
0,81 a 1,00 & muito bom \\
\hline
\end{tabular}

Tabela 2 - Coeficiente de Kappa da concordância para avaliação do teste intra e inter-examinadores.

\begin{tabular}{cccc}
\hline examinadores (n=2) & $\begin{array}{c}\text { nível de } \\
\text { concordância }\end{array}$ & $\begin{array}{c}\text { \% de } \\
\text { concordância }\end{array}$ & $\mathbf{k}$ \\
\hline Ex1 Av1 x Ex1 Av2 & bom & 76,33 & 0,68 \\
Ex1 Av1 x Ex2 & bom & 68,64 & 0,57 \\
Ex1 Av2 x Ex2 & bom & 74,56 & 0,65 \\
\hline
\end{tabular}


sutural e, sobretudo, da subseqüente ossificação da sutura palatina mediana na clínica é feito com as radiografias oclusais totais de maxila, obtidas em épocas oportunas, obrigatoriamente no final da fase passiva do procedimento de expansão rápida.

A sutura palatina mediana tem estrutura semelhante às demais suturas cranianas e faciais, formada por tecido conjuntivo fibroso organizado, com feixes de fibras colágenas paralelos entre si e em relação às margens ósseas, contendo células e vasos sanguíneos $^{6,14}$, e ainda regiões sugerindo remodelação óssea natural, com atividade osteoblástica e osteoclástica ${ }^{16,17}$, principalmente no estágio correspondente à dentadura mista ${ }^{17}$. Na imagem radiográfica de uma sutura com características de normalidade, como na encontrada no estágio préexpansão, a sutura palatina mediana apresenta-se como uma área estreita e radiolúcida, limitada por um osso bem mineralizado. Esta descrição corrobora outros escritos ${ }^{4,5,13,19,20}$. A imagem da sutura palatina mediana é particularmente vista com clareza até a metade do palato (Fig. 1,2). A partir daí, seu contorno perde a nitidez, provavelmente pela superposição da imagem do vômer e ou superpo- sição da base do crânio, projetada na extremidade posterior do filme radiográfico, ou até mesmo pela interdigitação mais complexa da sutura palatina mediana na região posterior ${ }^{17}$.

Um ponto crucial que deve ser considerado pelo ortodontista que trabalha com a expansão rápida da maxila é relativo ao tempo que a sutura palatina mediana leva para se reorganizar estruturalmente. Tal preocupação torna-se importante quando se avalia a estabilidade pós-tratamento dos resultados obtidos com a expansão. Em levantamento recente realizado na casuística de expansão rápida da maxila em crianças no Curso de Ortodontia Preventiva e Interceptiva da Profis, descobriu-se que de cada quatro crianças que haviam se submetido a este procedimento na dentadura decídua, uma teve que passar novamente pelo processo em algum outro estágio do desenvolvimento da oclusão. Assim sendo, estipulou-se um protocolo de tratamento para a expansão rápida da maxila em crianças na fase de dentadura decídua e mista. Este protocolo inclui: (1) sobrecorreção, sem, no entanto, criar uma mordida cruzada inversa; (2) contenção com o aparelho expansor
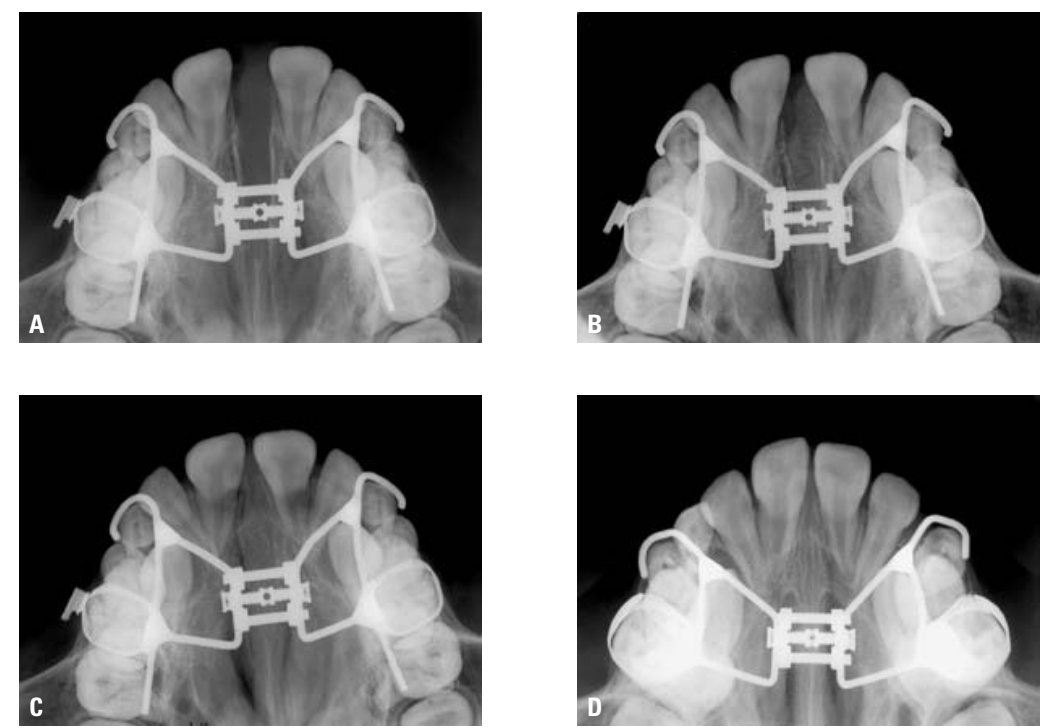

FIGURA 1 - Seqüência de radiografias oclusais totais de maxila, selecionada aleatoriamente de um paciente do grupo amostral, ilustrando o sistema de escores proposto pelos autores. 
mantido passivamente na boca até a completa ossificação da sutura palatina mediana; (3) contenção removível durante um ano após a suspensão do aparelho expansor tipo Haas e, finalmente, (4) eliminação de prováveis fatores etiológicos relacionados com a recidiva da atresia maxilar.

O presente trabalho refere-se ao item 2 do protocolo de tratamento do problema transversal na maxila, ou seja, à preocupação com a ossificação da sutura rompida. Esta inquietação por parte do ortodontista se refere à época em que a sutura já está completamente reorganizada para que o aparelho seja removido com alguma segurança. A Histologia demonstra que três meses não são suficientes para a reorganização total da sutura com nível de formação óssea compatível com o estágio pré-tratamento ${ }^{5,17}$, muito embora o processo de ossificação pós-expansão tenha início logo depois de terminada a fase ativa da expansão ${ }^{4}$.

A imagem radiográfica imediatamente após a fase ativa da expansão rápida da maxila mostrou, para todas as crianças examinadas, uma área radiolúcida ampla na região da sutura palatina mediana, como já mencionado na literatura ${ }^{13,15}$. Esta área radiolúcida se apresentou bem definida pelas margens da sutura, nitidamente separadas pela ativação do aparelho expansor, o que se denominou "margens da sutura velha" (Fig. 2B). Essas margens são visualizadas na imagem radiográfica como uma linha radiopaca bem definida e demarcada, sempre na região pré-maxilar ou pelo menos até a metade do palato duro. A partir desta extensão, a nitidez das margens torna-se menor. A área radiolúcida, visualizada entre as margens da sutura velha, caracteriza-se por uma região hipomineralizada, em forma triangular ou trapezoidal.
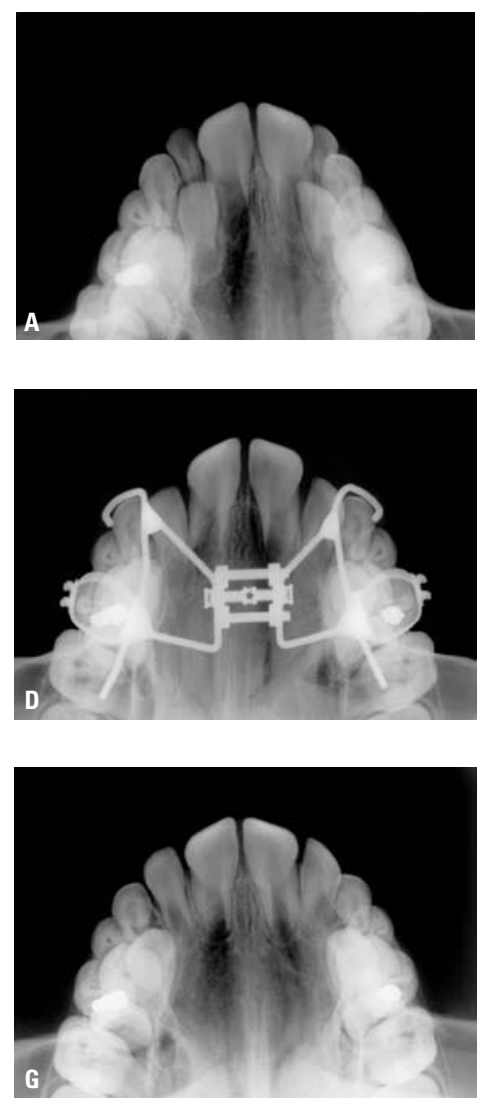
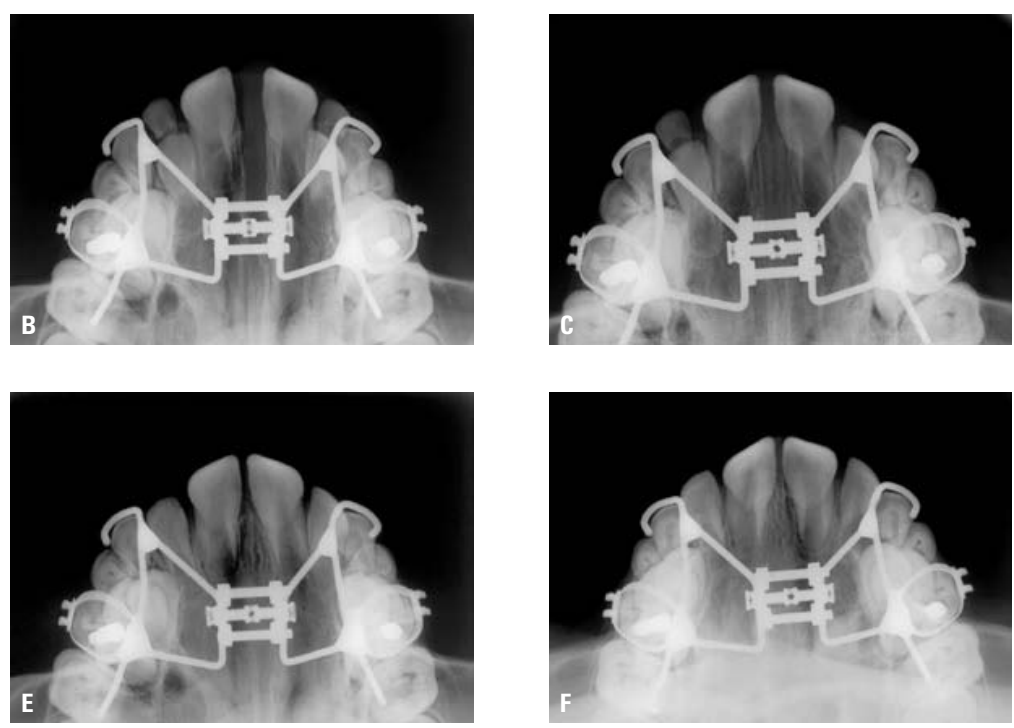

FIGURA 2 - Seqüência radiográfica ilustrando como é visualizada a região da sutura palatina mediana por meio de radiografias oclusais de maxila. A seqüência ilustra as radiografias tomadas antes do procedimento de expansão rápida da maxila, evidenciando a integridade sutural (A); após a fase ativa de expansão, com a abertura da sutura palatina mediana (B) e no período de contenção, com evidências de neoformação óssea durante todo o período de acompanhamento (C-G). Essas radiografias foram tomadas para fins de pesquisa. Com finalidade clínica, radiografias tomadas mensalmente não se justificam. Via de regra, a radiografia oclusal de maxila é solicitada na fase de pré-expansão e após 6 meses de contenção com 0 aparelho expansor passivo. 
Tabela 3 - Distribuição dos escores e o cálculo da mediana para os escores atribuídos por um examinador na radiografia oclusal de maxila no terceiro mês pós-expansão.

\begin{tabular}{|c|c|c|}
\hline Escore & $\mathbf{n}$ & $\%$ \\
\hline 1 & 0 & 0,0 \\
\hline 2 & 2 & 8,6 \\
\hline 3 & 23 & 65,7 \\
\hline 4 & 9 & 25,7 \\
\hline Mediana & & \\
\hline
\end{tabular}

A sutura palatina mediana é uma sutura adaptável aos impactos mecânicos produzidos pela expansão rápida da maxila, pelo menos no estágio de dentadura mista. Nas 38 crianças avaliadas no presente estudo, a sutura palatina mediana foi rompida durante a fase ativa da expansão rápida da maxila, sem nenhuma intercorrência que justificasse a suspensão do procedimento antes do período determinado.

A ossificação da sutura palatina mediana iniciase imediatamente após a disjunção maxilar. Em trabalhos histológicos, há evidência de ossificação após quinze dias de tratamento ${ }^{4}$. No entanto, o que se observou nas imagens radiográficas é que a ossificação não se completou até o terceiro mês de acompanhamento pós-expansão (Tab. 3). Em apenas $25 \%$ das radiografias analisadas, a imagem da sutura palatina mediana apresentou evidências de neoformação óssea completa no terceiro mês de controle. A maioria dos pacientes, totalizando $65 \%$ do grupo amostral, não apresentou sinal de total neoformação óssea. Tal constatação sugere a necessidade de obtenção de uma radiografia oclusal de maxila por volta do terceiro mês de contenção e não antes deste período. Esta imagem determinará a condição da sutura e, por conseqüência, a época provável de finalização da contenção, ou em outras palavras, a época de suspensão do aparelho expansor.

$\mathrm{Na}$ clínica de Ortodontia, em crianças na fase de dentadura decídua e mista quando não há planejamento de mecânica subseqüente, recomendase manter o aparelho expansor como contenção até 6 meses após a abertura da sutura palatina mediana. Completados os 6 meses de contenção com o aparelho passivo, uma radiografia oclusal de maxila é solicitada para avaliação do nível de ossificação da sutura. A presença da sutura nova ossificada é um indicativo de que o aparelho já pode ser removido e uma contenção removível é, então, instalada, com o objetivo de minimizar os efeitos da recidiva.

\section{CONCLUSÕES}

Observou-se uma variação individual quanto ao período necessário para a neoformação óssea sutural durante a fase de contenção, o que justifica a imagem radiográfica como determinante da época propícia para a remoção do aparelho expansor. Tendo em vista a estabilidade pós-tratamento a longo prazo, o aparelho expansor deve ser removido somente depois que a nova sutura estiver completamente estabelecida. Os resultados revelaram que são necessários pelo menos três meses para a completa neoformação óssea da sutura palatina mediana, mediante análise da imagem radiográfica oclusal, durante a fase passiva da expansão rápida da maxila. Entretanto, devido à variação individual no tempo de ossificação da sutura e visando menor efeito de recidiva, recomenda-se que o aparelho seja mantido passivo por pelo menos 6 meses. A imagem avaliada radiograficamente se mostrou confiável para a determinação da época correta de remoção do aparelho expansor. 


\title{
Midpalatal suture ossification post rapid palatal expansion: a radiographic study
}

\begin{abstract}
Objective: the current study aims at following up radiographically the evolution of the midpalatal suture during the expansion procedure since the opening of the suture until bone formation. Methods: the sample comprised 38 patients in the mixed dentition stage submitted to the rapid palatal expansion protocol of the Hospital for Rehabilitation of Craniofacial Anomalies. Results: it was observed an individual variation on the period of bone ossification of the midpalatal suture, which justifies the radiographic follow-up as determinant for the appliance removal. Due to long-term post-treatment stability, the expander should be removed after the new suture is completely formed. Conclusions: the findings show that it is necessary more than three months for the complete reorganization of the midpalatal suture during the passive phase of the rapid palatal expansion.
\end{abstract}

Key words: Rapid maxillary expansion. Diagnostic imaging. Orthodontics. Suture.

\section{REFERÊNCIAS}

1. ALTMAN, D. G. Practical statistics for medical research. London: Chapman \& Hall, 1991.

2. ANGELL, E. H. Treatment of irregularity of the permanent or adult teeth. Part 1. Dent. Cosmos, Philadelphia, v. 1, no. 10, p. 540-544, May 1860.

3. ANGELL, E. H. Treatment of irregularity of the permanent or adult teeth. Part 2. Dent. Cosmos, Philadelphia, v. 1, no. 10, p. 599-600, June 1860.

4. BRIN, I. et al. Rapid palatal expansion in cats: effect of age on sutural cyclic nucleotides. Am. J. Dentofacial Orthop., St. Louis, v. 79, no. 2, p. 162-175, Feb. 1981.

5. CLEALL, J. F. et al. Expansion of the midpalatal suture in the monkey. Angle Orthod. Appleton, v. 35, p. 23-35, Jan. 1965.

6. DEBBANE, E. F. A cephalometric and histologic study of the effect of orthodontic expansion of the midpalatal suture of the cat. Am. J. Orthod., St. Louis, v. 44, no. 3, p. 187-219, Mar. 1958.

7. DEWEY, M. Development of the maxillae with reference to opening the median suture. Dent. Items Interest., Brooklyn, v. 35, p. 189-208, 271-282, 1913.

8. EKSTROM, C.; HENRIKSON, C. O.; JENSEN, R. Mineralization in the midpalatal suture after orthodontic expansion. Am. J. Orthod., St. Louis, v. 71, no. 4, p. 449-455, Apr. 1977.

9. ENNES, J.; CONSOLARO, A. Sutura palatina mediana: avaliação do grau de ossificação em crânios humanos. Rev. Dental Press Ortodon. Ortop. Facial, Maringá, v. 9, n. 5, p. 64-73, set./out. 2004.

10. HAAS, A. J. The treatment of maxillary deficiency by opening the midpalatal suture. Angle Orthod., Appleton, 35, no. 3, p. 200-217, July 1965.

11. HAAS, A. J. Rapid expansion on the maxillary dental arch and nasal cavity by opening the midpalatal suture. Angle Orthod., Appleton, v. 31, no. 2, p.73-90, Apr. 1961.
12. HOFFER JUNIOR, F. L.; WALTERS, R. D. Adaptative changes in the face of the Macaca mulatta monkey following orthopedic opening of the midpalatal suture. Angle Orthod., Appleton, v. 45 , no. 4, p. 282-290, Oct. 1975.

13. INOUE, N. et al. Radiographic observation of rapid expansion of human maxilla. Bull Tokyo Med. Dent. Univ., Tokyo, v. 17 no. 3, p. 149-161, Sept. 1970.

14. LATHAM, R. A. The development, structure and growth pattern of the human midpalatal suture. J. Anat., London, v. 108, no. 1, p. 31-41, Jan. 1971.

15. MELSEN, B. A histological study of the influence of sutural morphology and skeletal maturation on rapid palatal expansion in children. Trans. Eur. Orthod. Soc., London, p. 499-507, 1972.

16. MURRAY, J. M.; CLEALL, J. F. Early tissue response to rapid maxillary expansion in the midpalatal suture of the rhesus monkey. J. Dent. Res., Alexandria, v. 50, no. 6, p. 1654-1660, Nov./Dec. 1971.

17. OHSHIMA, O. Effect of lateral expansion force on the maxillary structure in cynomolgus monkey. J. Osaka Dent. Univ., Osaka, v. 6, no. 1, p. 11-50, Apr. 1972.

18. SIMÕES, F. X. P. C.; ARAÚJO, T. M.; BITTENCOURT, M. A. V. Avaliação da maturação óssea na sutura palatina mediana, após expansão rápida da maxila, por meio da imagem digitalizada. Rev. Dental Press Ortodon. Ortop. Facial, Maringá, v. 8, n.1, p. 59-67, jan./fev. 2003.

19. STARNBACH, H. et al. Facioskeletal and dental changes resulting from rapid maxillary expansion. Angle Orthod., Appleton, v. 36, no. 2, p. 152-164, Apr. 1966.

20. WALTERS, R. D. Facial changes in the Macaca mulatta monkey by orthopedic opening of the midpalatal suture. Angle Orthod., Appleton, v. 45, no. 3, p. 169-179, July 1975.

\section{Endereço para correspondência}

Omar Gabriel da Silva Filho

Setor de Orto. do Hosp. Reab. de Anomalias Craniofaciais da USP Silvio Marchione, 3-20 Vila Universitária

CEP: 17.012-900 - Bauru/SP

E-mail: ortoface@travelnet.com.br 